\title{
A study on prescription analysis of referral dog bite cases to anti rabies clinic of M.K.C.G. Medical College, Berhampur, India
}

\author{
Tapas Ranjan Behera ${ }^{1}$, Gurukrushna Mohapatra ${ }^{2}$, Biswabara Rout ${ }^{3}$
}

\begin{abstract}
${ }^{1}$ Assistant Professor, Department of Community Medicine, SCB Medical College, Cuttack, Odisha, India. ${ }^{2}$ Assistant Professor, Department of Community Medicine, KIMS, Bhubaneswar, Odisha, India. ${ }^{3}$ Assistant Professor, Department of Physiology, SCB Medical College, Cuttack, Odisha, India.
\end{abstract}

\section{Abstract}

Dog bites in human are a serious public health problem and have been well documented worldwide. As rabies is not a notifiable disease in India and most deaths occur in rural areas where surveillance is poor. The objective of this study to assess the drug prescription patterns of referral cases of dog bite attending in the anti-rabies clinic (ARC) of Department of Community Medicine at MKCG Medical College. For this particular study 606 prescriptions were collected over a six months period. Suspected referred dog bite cases to ARC and willing to participate in the study were included as study subjects. Prescriptions Patients' identity (name, age, sex) and date of prescription were present in all cases, address was written correctly in only $30 \%$ cases. $88 \%$ of the prescriptions were legible. Majority prescriptions (44\%) were referred from of primary health centers and community health centers. Nearly one third of referred patients had not received anti rabies vaccine. Only 5\% cases were administered with rabies immune globulin and about $30 \%$ had taken oral antibiotics which were referred from PHCs/CHCs. Specific treatment to dog bite (i.e. use of vaccine \& RIG) was lacking in the prescription whereas Co-prescription of other drugs (i.e. antibiotics, pain killers, vitamins) were mentioned in the prescription. Regular prescription auditing with training of Medical Officers on essential drug availability should be undertaken by the Govt. of Odisha in order to give rationality to all prescriptions.

Keywords: Rabies, Prescriptions, Rabies vaccine, Rabies immunoglobulin, India.

\section{Introduction}

Dog bites in human are a serious public health problem and have been well documented worldwide. ${ }^{1,2}$ In the United States, 4.7 million people were estimated to have been bitten by dogs in 1994 (an incidence rate of $16.1 / 1000$ in adults and 24.5/1000 in children), of whom 800,000 required medical treatment. ${ }^{3}$ The annual estimated number of dog bites in India is 17.4 million, leading to estimated 18,000-20,000 cases of human rabies per year. ${ }^{4}$ Rabies, which is a $100 \%$ fatal and $100 \%$ preventable disease, mainly occur by dog bite. As rabies is not a notifiable disease in India and most deaths occur in rural areas where surveillance is poor, it is widely believed that this figure may be an underestimate. In the past, a large proportion of rabies patients did not receive any vaccination, and many did not complete the full course. $^{5}$ In the periphery Primary Health Centres (PHCs) and Community Health Centres (CHCs) of the state, vaccine as well Rabies Immunoglobulin (RIG) is at scarce or even not in supply. The Govt. of Odisha has supplied Anti Rabies Vaccine (ARV) to all District Head Quarter Hospitals (DHH) and designated Anti Rabies Clinic (ARC) at CHC but RIG is available only at Tertiary Care Hospitals. After introduction of IDRV in the state none of the Medical Officers (MOs) were given training on management of animal bite. However a guideline on the same has been prepared and circulated to all DHH which might have not reached to all $\mathrm{CHC} / \mathrm{PHC}$. Also the health care professionals are not aware about the correct procedure for the management of dog bite cases. That is why majority dog bite cases are referred to the tertiary care centre.

\section{Practice Points}

- Number of dog bites in India is 17.4 million, leading to estimated $18,000-20,000$ cases of human rabies per year.

- Approximately $44 \%$ prescriptions were referred from of primary health centres and community health centres.

- $\mathrm{Rx}$ or superscription was present in $87 \%$ cases.

- In $95 \%$ prescriptions, site of bite was not mentioned and in $92 \%$ prescriptions categorization of bite was not mentioned.

- Basic essential requirements for management of dog bite like vaccines and rabies immunoglobulins should be available at the levels of $\mathrm{PHC} / \mathrm{CHC}$.

A prescription $(\mathrm{R})$ is a health-care program implemented by a physician in the form of instructions that govern the plan of care for an individual patient. ${ }^{6}$ A prescription include Superscription or heading, Inscription or main body of the prescription, Subscription or directions to the compounder, Prescriber's signature, seal of the prescriber. To know actual management for a certain disease given in different health care level, prescription act as only the key material in this aspect. ${ }^{7}$ Communication is essential for

Correspondence: Dr Tapas Ranjan Behera, Assistant Professor, Department of Community Medicine, SCB Medical College, Cuttack, Odisha, India. Email: tapas4behera@gmail.com. 
the effective delivery of health care, and is one of the most powerful tools in a clinician's arsenal. Unfortunately, there is often a mismatch between a clinician's level of communication and a patient's level of comprehension. In fact, evidence shows that patients often misinterpret or do not understand much of the information given to them by clinicians. This lack of understanding can lead to medication errors, missed appointments, adverse medical outcomes, and even malpractice lawsuits. ${ }^{8}$

'Information therapy' (Ix) is an attempt to provide patients with the timely, adequate and evidence-based health information for making informed decision regarding their treatment. The information provided should be relevant, accurate, complete, reliable, easy to understand and practical. Ix is exactly like treatment prescription by a physician but it also includes reference to healthcare information resources to patients following a clinical visit. ${ }^{9}$ On an average $80-100$ patients are attended at the Anti-Rabies Clinic (ARC) for the treatment of mainly Category II \& III dog bite cases daily in the MKCG Medical College Hospital, Berhampur, Odisha and among them more than 50\% were referred cases. Base on this background it was planned to conduct a study with objective to assess the drug prescription patterns of referral cases of dog bite attending in the antirabies clinic (ARC) of Department of Community Medicine at MKCG Medical College, Hospital, Berhampur, Odisha.

\section{Materials and methods}

\section{Study design \& study setting}

It was a cross-sectional study carried out in Anti-rabies clinic of Department of Community Medicine, M.K.C.G. Medical College, Berhampur, Odisha, India between January 2015 to June 2015.

\section{Sample size and sampling technique}

The WHO document titled: 'How to investigate drug use in health facilities' mentioned that at least 600 encounters should be included in a cross-sectional survey to describe the current prescribing practices, with a greater number, if possible. ${ }^{9}$ For this particular study 606 prescriptions were collected over a six months period. Suspected referred dog bite cases to the ARC and willing to participate in the study were included as study subjects. Severely injured patients and those not willing to participate were excluded from the study. All the communications were done in local language that is Odia.

\section{Study instrument}

In a pre-designed pre-tested Performa, relevant data were collected from the prescriptions of referred dog bite cases attending the ARC during the study period. This Performa had two parts. Part A consisted of different components of prescription like patient information, date and legibility of prescription, $\mathrm{Rx}$, detailed clinical history, signature. Part B consisted of management of dog bite like washing of wound, taking tetanus toxoid, Anti rabies vaccine and rabies immunoglobulin (RIG).

\section{Data collection}

After obtaining the permission from the Superintendent of the MKCG Medical College and hospital, prescriptions of the patients of referred dog bite cases to
ARC were collected every day. Five days per week and 4-5 prescriptions per day were taken for data collection in the Performa. Data was not collected in government holidays. Collected data were entered in SPSS version 16.0 and analysed.

\section{Results}

Out of total 606 prescriptions Patients' identity (name, age, sex) and date of prescription were present in all cases; however, address was written correctly in only $30 \%$ cases. About $88 \%$ of the prescriptions were legible and $12 \%$ prescriptions can be read with some difficulty. Majority prescriptions (44\%) were referred from of primary health centers and community health centers followed by private practitioners within the district $(18 \%)$ and $8 \%$ prescriptions referred from other districts. It was also noted that $15 \%$ of the prescriptions were referred from causality of the same hospital (Table 1). $\mathrm{Rx}$ or superscription was present in $87 \%$ cases. $60 \%$ had no referral slips. About $79 \%$ participants were male and majority $76 \%$ dog bite cases were from rural areas. $63 \%$ belonged to age group $15-45$ yrs age group and only $4 \%$ were less than 5 yrs of age.

In $94 \%$ cases tetanus toxoid was given and vaccine was administered i.e. purified vero cell rabies vaccine (PVRV) to $71 \%$ of cases. Nearly one third of referred patients had not received any type of anti-rabies vaccine (ARV) and in $6 \%$ of the referred cases ARV was administered over gluteal region. The vaccine administered to deltoid or thigh region in $65 \%$ cases. In $95 \%$ prescription site of bite was not mentioned. Similarly in $92 \%$ prescription no categorization of bite was mentioned. In $78 \%$ cases, wound washing was not advised. Only $5 \%$ cases were administered with rabies immune globulin (Table 2).

About $30 \%$ had taken oral antibiotics, $10 \%$ had injectable antibiotics. Similarly $15 \%$ patients had taken injectable pain killer where $50 \%$ were prescribed oral pain killer. Only $18 \%$ were prescribed with virucidal ointment, i.e. povidone iodine and $11 \%$ were prescribed with other ointments. Vitamin and other drugs prescribed in 5\% cases (Table 3 ).

Table 1: Source of references to the ARC

\begin{tabular}{|l|c|}
\hline \multicolumn{1}{|c|}{ Source of references } & Number (\%) \\
\hline Within District & $558(92 \%)$ \\
\hline Causality MKCG MCH & $90(15 \%)$ \\
\hline City Hospital (DHH Berhampur) & $54(9 \%)$ \\
\hline Sub Divisional Hospitals & $36(6 \%)$ \\
\hline PHC/CHC & $270(44 \%)$ \\
\hline Private Practitioners (MO) & $108(18 \%)$ \\
\hline Outside District & $48(8 \%)$ \\
\hline Total & $\mathbf{6 0 6}(\mathbf{1 0 0 \% )}$ \\
\hline
\end{tabular}

Table 2: Mention of different aspects of diagnosis and treatment in prescription

\begin{tabular}{|l|c|c|}
\hline $\begin{array}{l}\text { Mentioned in } \\
\text { prescription }\end{array}$ & Yes & No \\
\hline Site of bite & $30(5 \%)$ & $576(95 \%)$ \\
\hline Category of bite & $48(8 \%)$ & $558(92 \%)$ \\
\hline Advice of wound washing & $132(22 \%)$ & $474(78 \%)$ \\
\hline Tetanus toxoid given & $574(94 \%)$ & $32(6 \%)$ \\
\hline Vaccine administration & $432(71 \%)$ & $174(29 \%)$ \\
\hline RIG & $30(5 \%)$ & $576(95 \%)$ \\
\hline
\end{tabular}


Table 3: Co-prescription pattern of referral cases with respect to treatment

\begin{tabular}{|c|c|c|c|c|c|c|c|c|c|c|c|c|c|}
\hline \multirow[t]{2}{*}{ Source } & \multirow[t]{2}{*}{ 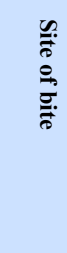 } & \multirow{2}{*}{ 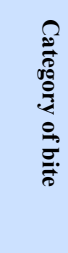 } & \multirow{2}{*}{ 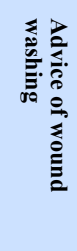 } & \multirow{2}{*}{ 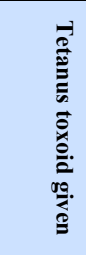 } & \multirow{2}{*}{ 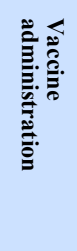 } & \multirow[t]{2}{*}{$\frac{\pi}{\Omega}$} & \multicolumn{2}{|r|}{$\begin{array}{l}\text { D. } \\
\text { है. } \\
\text { : }\end{array}$} & \multicolumn{2}{|r|}{ 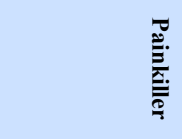 } & \multicolumn{2}{|r|}{ 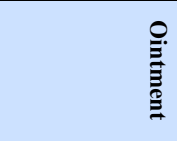 } & \multirow{2}{*}{ 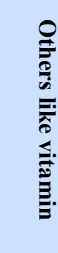 } \\
\hline & & & & & & & $\Xi$ & 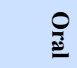 & $\Xi$ & \begin{tabular}{l}
0 \\
\hdashline
\end{tabular} & 을 & $\stackrel{ᄋ}{\stackrel{0}{\leftrightarrows}}$ & \\
\hline \multicolumn{14}{|l|}{ A. Within district } \\
\hline Casuality MKCG MCH & 5 & 6 & 16 & 88 & 65 & 1 & 7 & 22 & 11 & 35 & 16 & 11 & 11 \\
\hline City hospital (DHH Berhampur) & 2 & 4 & 11 & 52 & 37 & 9 & 5 & 24 & 13 & 31 & 11 & 7 & 5 \\
\hline Sub divisional hospitals & 2 & 3 & 8 & 42 & 24 & 0 & 3 & 4 & 2 & 18 & 7 & 4 & 4 \\
\hline $\mathrm{PHC} / \mathrm{CHC}$ & 14 & 19 & 58 & 235 & 190 & 10 & 31 & 89 & 45 & 140 & 46 & 35 & 5 \\
\hline Private practioners (MO) & 5 & 8 & 20 & 97 & 78 & 9 & 10 & 28 & 13 & 48 & 20 & 9 & 4 \\
\hline B. Outside district & 2 & 8 & 19 & 60 & 38 & 1 & 5 & 13 & 8 & 32 & 10 & 4 & 1 \\
\hline Total & $\begin{array}{c}30 \\
(5 \%)\end{array}$ & $\begin{array}{c}48 \\
(8 \%)\end{array}$ & $\begin{array}{c}132 \\
(22 \%)\end{array}$ & $\begin{array}{c}574 \\
(94 \%)\end{array}$ & $\begin{array}{c}432 \\
(71 \%)\end{array}$ & $\begin{array}{c}30 \\
(5 \%)\end{array}$ & $\begin{array}{c}61 \\
(10 \%)\end{array}$ & $\begin{array}{c}180 \\
(30 \%)\end{array}$ & $\begin{array}{c}92 \\
(15 \%)\end{array}$ & $\begin{array}{c}304 \\
(50 \%)\end{array}$ & $\begin{array}{c}110 \\
(18 \%)\end{array}$ & $\begin{array}{c}70 \\
(11 \%)\end{array}$ & $\begin{array}{c}30 \\
(5 \%)\end{array}$ \\
\hline
\end{tabular}

\section{Discussion}

In the present study, addresses were written correctly in $30 \%$ cases where in a study conducted by Pushpender et $a l .{ }^{10}$ on prescribing pattern on rational therapy the correct address were written only in $5 \%$ cases. In this study, $79 \%$ were male where another study conducted by Das et $a .^{11}$ on pattern of injury by animal bite attending OPD, among the patients, males (69\%) were more found to have animal caused injury than females.

Majority of the prescriptions $(88 \%)$ were legible in this study where in contrast a study done by Bhattacharya et $a l .{ }^{12}$ on prescription pattern in a tertiary hospital, only $37 \%$ prescriptions were found to be legible. In this study $30 \%$ had taken oral antibiotics, $10 \%$ had injectable antibiotics where another study conducted by Desalegn $^{13}$ on assessment of drug use pattern using the WHO prescribing indicators at Hawassa University teaching and referral hospital, oral antibiotics prescribed in $58 \%$ cases and injectable in $38 \%$ cases.

A study done by vargo et al. ${ }^{14}$ on incidence of dog bite in American Samoa it was found that Males 5 to 14 years of age and females 5 to 19 years were most likely to be bitten i.e. ( $23 \%)$ and $(46 \%)$ respectively where as in this study maximum dog bite cases belonged to age group $15-44 y r s(63 \%)$. In this study washing of wound advised to $22 \%$ cases where another study conducted by Ana Mustiana et al. ${ }^{15}$ washing done by $34 \%$ of cases.

\section{Conclusion}

Prescription analysis of a health facility not only gives an idea of services available and need of referral for further treatment but also it gives a light on the diagnosis, treatment aspect mentioned in the prescription or not. Despite many of the management facilities available in the $\mathrm{PHC} / \mathrm{CHC}$ still doctors referred dog bite cases to higher health facility for further treatment with unnecessary co-prescription of antibiotics and pain killers. Hence availability of basic requirements like vaccines and rabies immunoglobulins at the levels of $\mathrm{PHC} / \mathrm{CHC}$ can decrease the load at tertiary hospitals and also the out of pocket expenditure of patients.

\section{Competing interest}

The authors declare that they have no competing interests.

\section{References}

1. Overall KL, Love M. Dog bites to humansdemography, epidemiology, injury, and risk. $J$ Am Vet Med Assoc 2001; 218(12):1923-34.

2. Ozanne-Smith J, Ashby K, Stathakis VZ. Dog bite and injury prevention-analysis, critical review, and research agenda. Inj Prev 2001;7 (4):321-6.

3. Sacks JJ, Kresnow M, Houston B. Dog bites: How big a problem? Inj Prev 1996;2(1):52-4.

4. Gongal $\mathrm{G}$, Wright AE. Human rabies in the WHO southeast Asia region: Forward steps for elimination. Adv Prev Med 2011; Article ID 383870 .

5. Sudarshan MK, Mahendra BJ, Madhusudana SN, Ashwoath Narayana DH, Rahman A, Rao NS, et al. An epidemiological study of animal bites in India; results of a WHO sponsored national multi-centric rabies survey. $J$ Commun Dis 2006;38:32-9.

6. Belknap SM, Moore H, Lanzotti SA, Yarnold PR, Getz M, Deitrick DL, et al. Application of software design principles and debugging methods to an analgesia prescription reduces risk of severe injury from medical use of opioids. Clin Pharmacol Ther 2008;84(3):38592.

7. Basukala S, Mehrotra S. Reducing medication error: A retrospective audit of drug prescriptions in a tertiary care hospital. IJAPBS 2015;4(8):26-32.

8. Weiss B. Health literacy and patient safety: Help patients understand. Manual for clinician. $2^{\text {nd }}$ edition. Chicago: American Medical Association, 2009.

9. Sonika R, Sharma, VL Singh A. Information therapy: Bridging gap between doctors and patients. South East Asia J Public Health 2014;4(2):47-50.

10. World Health Organization. How to investigate drug use in health facilities: selected drug use indicators. Geneva: WHO, 1993. 
11. Sharma P, Kapoor B. Study of Prescribing pattern for rational drug therapy. JK Science 2003;5(3):107-9.

12. Das D, Mandal A, Haldar S, Das J, Bandopadhyay B, Naskar S. Pattern of injuries caused by animal and management among patients attending at out-patient department of a rural medical college, West Bengal, India. IOSR J Dental Med Sci 2015;14(4):55-9.

13. Bhattacharya A, Gupta $\mathrm{H}$, Dewangan MK. Prescription pattern study of the drugs used in tertiary hospitals of the Bilaspur region. A sian $J$ Pharm Clin Res 2012;5(4):73-6.

14. Desalegn A. Assessment of drug use pattern using WHO prescribing indicators at Hawassa University teaching and referral hospital, south Ethiopia: A cross-sectional study. 2013;13:170.
15. Vargo D, Pasquale J, Vargo A. Incidence of dog bite injuries in American Samoa and their impact on society. Hawaii J Med Public Health 2012;71 (1):6-12.

16. Mustiana A, Toribio J-A, Abdurrahman M, Suadnya IW, Hernandez-Jover M, Putra AAG, et al. Owned and unowned dog population estimation, dog management and dog bites to inform rabies prevention and response on Lombok island, Indonesia. PLOS ONE 2015;10 (5): $\mathrm{e} 0124092$. 